\title{
Prevalence of Speech Sound Disorders among Primary School Children
}

\author{
Iqra Aslam ${ }^{1}$, Nazia Mumtaz ${ }^{2}$, Ghulam Saqulain ${ }^{3}$ \\ ${ }^{1}$ Speech Language Pathologist, PAF School for Persons with Special Needs, PAF Base Mushif, Sargodha, Pakistan \\ ${ }^{2}$ Head, Department of Speech Language Pathology, Riphah International University, Islamabad, Pakistan \\ ${ }^{3}$ Head, Department of Otorhinolaryngology \& Head and Neck Surgery, Capital Hospital PGMI, Islamabad, Pakistan
}

\begin{abstract}
AB STRACT
Background: Communication Disorders are common and affect individual's abilities to comprehend, detect and use language and speech, with speech sound disorders (SSD) being the most common communication issue of the youth. SSD is a disorder of development with difficulty in articulation and phonology affecting understanding and intelligibility of speech of a child. It affects the scholarly accomplishment in school as well. The objective of this study was to determine the prevalence of speech sound disorders among primary school going children.

Material and Methods: This was a cross-sectional study, recruiting a sample of 377 children through probability sampling technique from May 2018 to December 2018. Students of both genders, aged 4 to 8 years, were enrolled from Government Primary Schools of Mandi Bahauddin District, Punjab Pakistan. Students from private and special schools were excluded. Tool for Assessment of Articulation and Phonology in Urdu (TAAPU) was used to collect data, followed by data analysis using SPSS version 20.

Results: Of 377 primary school children, 167(44.3\%) were males and $210(55.7 \%)$ were females with a male to female ratio of $1: 1.26$. Speech Sound Disorder was detected in $5(1.3 \%)$ children, 4 males and only 1 female. Of these 5 cases with SSD, $3(60 \%)$ males suffered from substitution and $1(20 \%)$ from omission, while $1(20 \%)$ female child suffered from substitution disorder.

Conclusions: The prevalence of Speech Sound Disorders in primary school children is very low being $1.3 \%$, with significantly higher prevalence in males aged 61-72 months. "Substitution" of sounds is more common compared to "omission".

Key words: Articulation Disorder, Communication Disorder, Prevalence, Primary School Children, Speech Sound Disorder

\begin{tabular}{lll}
\hline Authors' Contribution: & Correspondence: & Article info: \\
${ }^{1}$ Conception; Literature research; & Ghulam Saqulain & Received: February 4, 2019 \\
manuscript design and drafting; ${ }^{2,3}$ Critical & Email:ghulam_saqulain@yahoo.com & Accepted: September 15, 2020 \\
analysis and manuscript review; Data & & \\
analysis; Manuscript Editing. & & \\
\hline
\end{tabular}
\end{abstract}

Cite this article. Aslam I, Mumtaz N, Saqulain G. Prevalence of Speech Sound Disorders among Primary School Children. J Islamabad Med Dental Coll. 2020; 9(3): 195-200. Doi:

Funding Source: Nil 10.35787/jimdc.v9i3.283

Conflict of Interest: Nil

\section{Introduction}

Communication Disorders (CD) are deep rooted issues. They influence social and emotional well- being, cognition and conduct and are also related to poor school performance, psychosocial, language 
and literacy problems. ${ }^{1}$ Speech sound disorder (SSD), voice disorders and fluency disorders (stuttering) are the three CD's traditionally referred to as speech disorder, with SSD being the most prevalent compared to other CDs. ${ }^{2}$ SSD is a disorder of development with difficulty in articulation and phonology which also affects understanding and intelligibility of child's speech, though there is no associated structural, motor, cognitive and affective deficits with the child. ${ }^{3}$ According to Tkach et al. SSD results from deficiency of phonological memory, ${ }^{4}$ and is a risk factor for language and a problem for literacy in later life. ${ }^{5}$ Most children in the process of child development commit errors as they figure out how to say new words, ${ }^{2}$ with SSD occurring when this continues past a particular age i.e. the inability or difficulty of the child to use speech sounds which are appropriate according to age for an individual dialect. $^{6}$ SSDs include four broad categories including, "Omission", in which sounds/ syllables are missed out by the child; "Additions" or "commissions", in which child adds an extra syllable or sound; "Distortions", in which though the child pronounces the word properly, however one of the sound is not correct and; "Substitution", in which child substitutes a sound for another sound.

Controversies on the classification of SSD in children still exist with proposed systems based on approaches including etiological, descriptive linguistic and processing. ${ }^{7}$ Communication disorders like SSD have immediate and delayed consequences for the child, which may include poor scholastic accomplishment in school years and other social and psychological consequences with an effect on professional decisions later in adulthood. ${ }^{8}$ No recommendation exists for formal screening to detect speech and language disorder in children through 5 years of age. According to Sui, there is no sufficient evidence for benefit of screening in 5 years and younger children for speech language delay. ${ }^{9}$ However, Arshad et al. concluded in a local study at Mayo Hospital Lahore, that family history as well as socioeconomic status were risk factors for speech and language disorders and recommended further research. ${ }^{10}$ Similarly Wallace et al. in their review noted deficiencies in the research base and highlighted the varieties of studies needed. ${ }^{11}$

Therefore, the current study was conducted to determine the prevalence of Speech sound disorder among primary school children. This study is important since there is dearth of literature available from this part of the world on this important issue. This information might also be important for rehabilitation by early identification and timely intervention.

\section{Material and Methods}

This cross-sectional study was conducted to determine the prevalence of speechsound disorders (SSD) in students attending primary schools of Mandi Bahauddin using probability sampling technique over a period of eight months from May 2018 to Dec 2018. This study was approved by the Advance Studies and Research Committee (ASRC), Isra Institute of Rehabilitation Sciences (IIRS), Isra University Islamabad. After calculating sample size using Raosoft software, the study enrolled 377 students of both genders, aged 4 to 8 years, studying in nine government primary schools of Mandi Bahauddin district, Punjab Pakistan. Informed consent was obtained from parents of children prior to inclusion in the study. Approval was also sought from the institutional heads/administrations of all the nine primary schools included in this study. Cases from private and special schools and those with any other disability were excluded.

Basic demographic sheet was used to collect data like age, gender, birth order, family system, number of siblings, class, and institution, while for the assessment of articulation and phonological disorders (APD) in regional language Urdu, Tool for Assessment of Articulation and Phonology in Urdu (TAAPU) ${ }^{12,13}$ was used. TAAPU is a locally developed 
tool and contains 60 colorful pictures for assessment. It uses a response sheet to record the response of children on a phonological sheet, listing the sounds in Urdu along with their phonetic transcription in English like / $/ / \mathrm{g} / / \mathrm{t} / / \mathrm{d} / / \mathrm{f} / / \mathrm{v} /$ etc. Errors in speech sounds generation is known as articulation error while phonological disorder is a patterned modification of speech system. For instance, fronting is process in which back sounds like /k/ and /g/ normally produced by tongue moving up in the back, get replaced with FRONT sounds $/ \mathrm{t} /$ and $/ \mathrm{d} /$ produced by the tongue coming up in the front. Other features of SSD's include omission and deletions, where child omit or delete certain sounds like "cu" for "cup", substitution in which sounds are substituted like "thing" for "sing" and additions, where sounds are added like "buhlack" for "black".

After approval from institutional heads and consent of parents, children were evaluated for SSD using TAAPU, by a senior speech therapist and responses recorded on the response sheet. Data was evaluated using SPSS version 21. Gender was presented in frequency and percentage, while age and TAAPU score was presented in mean and standard deviation.

\section{Results}

Of 377 primary school children, 167(44.3\%) were males and 210 (55.7\%) were females with a male to female ratio of 1:1.26. A low prevalence of SSD was noted in our study $(n=5 ; 1.3 \%)$ (Figure 1 ).

Of these 5 cases with SSD 4 (80\%) were males with 3 $(60 \%)$ suffering from substitution and $1(20 \%)$ from omission, while 1 (20\%) was a female child suffering from substitution (Table1). The mean age of sample population was $72.50 \pm 23.50$ months, mean birth order (mean of birth order of the affected child) was $1.12 \pm 0.58$ and siblings (mean of number of siblings) were $1.41 \pm 0.58$.

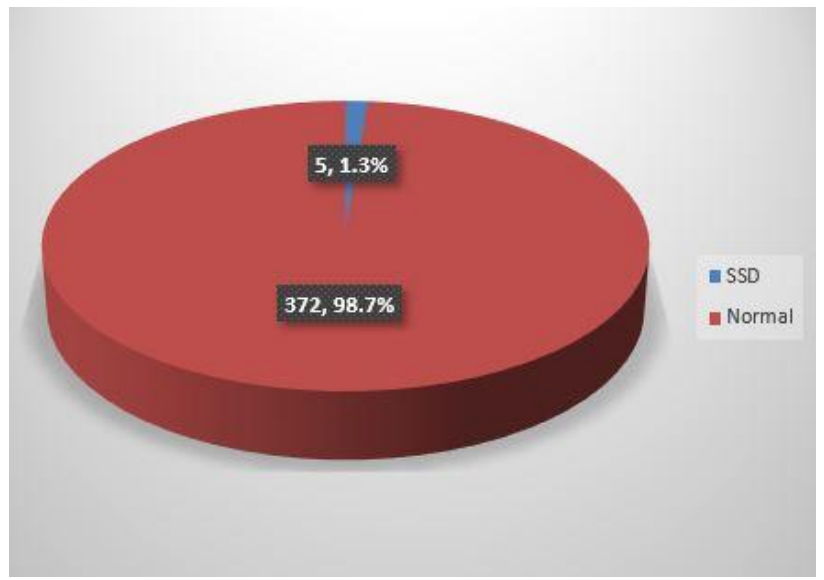

Figure I: Prevalence of Speech Sound Disorders (SSD) (n=377)

Statistical analysis revealed statistically significant difference between age groups and SSD and between gender and SSD with $p$-value of 0.025 .

The most common type of SSD in primary school children noted in the study was Substitution (80\%), followed by Omission (20\%) (Figure 2).

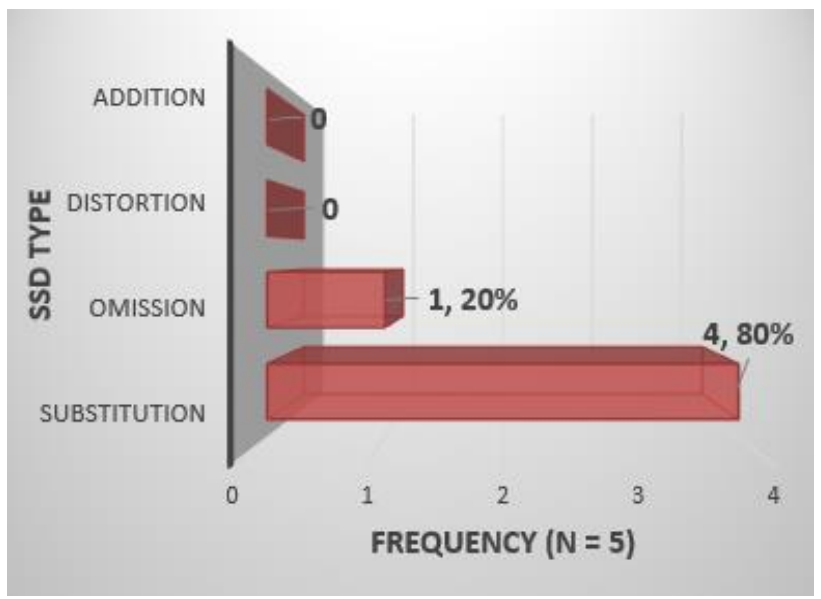

Figure 2: Frequency of different speech sound disorders (SSD) $(n=5)$

Table II shows the speech sound errors and their levels with one case substituting $/ \mathrm{k} /$ sound with $/ \mathrm{g} /$ at initial level, the other substituted $/ \mathrm{t} / \mathrm{with} / \mathrm{d} /$ at mid-level and third substituted/f/ with / $/$ / at initial level. One case omitted/ $t /$ at all levels and the other omitted/g/ sound at mid-level. 


\begin{tabular}{|c|c|c|c|c|c|c|c|}
\hline \multicolumn{2}{|c|}{ Demographic Variables } & \multicolumn{6}{|c|}{ Speech Sound Disorders (SSD) $(n=5)$} \\
\hline Variable & $\begin{array}{c}\text { Sample }(n=377) \\
n(\%)\end{array}$ & $\begin{array}{c}\text { Sub } \\
\text { n (\%) }\end{array}$ & $\begin{array}{l}\text { Omi } \\
n(\%)\end{array}$ & $\begin{array}{c}\text { Del } \\
\text { n (\%) }\end{array}$ & $\begin{array}{l}\text { Add } \\
n(\%)\end{array}$ & $\begin{array}{l}\text { Total } \\
\mathrm{n}(\%) \\
\end{array}$ & $* P$-value \\
\hline Gender & $\begin{array}{l}\text { Male: } 167(44.3) \\
\text { Female: } 210(55.7)\end{array}$ & $\begin{array}{l}3(60) \\
1(20)\end{array}$ & $\begin{array}{c}1(20) \\
0\end{array}$ & $\begin{array}{l}0 \\
0\end{array}$ & $\begin{array}{l}0 \\
0\end{array}$ & $\begin{array}{l}4(80) \\
1(20)\end{array}$ & 0.025 \\
\hline Age & $\begin{array}{l}49 \mathrm{~m}-60 \mathrm{~m}: 150(39.8) \\
61 \mathrm{~m}-72 \mathrm{~m}: 74(19.6) \\
73 \mathrm{~m}-84 \mathrm{~m}: 93(24.7) \\
84 \mathrm{~m}-96 \mathrm{~m} 60(15.9)\end{array}$ & $\begin{array}{c}0 \\
2(40) \\
1(20) \\
0\end{array}$ & $\begin{array}{c}1(20) \\
1(20) \\
0 \\
0\end{array}$ & $\begin{array}{l}0 \\
0 \\
0 \\
0\end{array}$ & $\begin{array}{l}0 \\
0 \\
0 \\
0\end{array}$ & $\begin{array}{c}1(20) \\
3(60) \\
1(20) \\
0\end{array}$ & 0.025 \\
\hline $\begin{array}{l}\text { Birth } \\
\text { Order }\end{array}$ & $\begin{array}{l}1-4: 238(63.1) \\
5-8: 120(31.8) \\
9-12: 19(05.0)\end{array}$ & $\begin{array}{l}2(40) \\
1(20) \\
1(20)\end{array}$ & $\begin{array}{c}1(20) \\
0 \\
0\end{array}$ & $\begin{array}{l}0 \\
0 \\
0\end{array}$ & $\begin{array}{l}0 \\
0 \\
0\end{array}$ & $\begin{array}{l}3(60) \\
1(20) \\
1(20)\end{array}$ & - \\
\hline Siblings & $\begin{array}{l}\text { 1- } 4: 238(63.1) \\
5-8: 120(31.8) \\
9-12: 19(5.0)\end{array}$ & $\begin{array}{l}2(40) \\
1(20) \\
1(20)\end{array}$ & $\begin{array}{c}1(20) \\
0 \\
0\end{array}$ & $\begin{array}{l}0 \\
0 \\
0\end{array}$ & $\begin{array}{l}0 \\
0 \\
0\end{array}$ & $\begin{array}{l}3(60) \\
1(20) \\
1(20)\end{array}$ & - \\
\hline $\begin{array}{l}\text { Family } \\
\text { System }\end{array}$ & $\begin{array}{l}\text { Nuclear: } 197(52.3) \\
\text { Joint: } 180(47.7)\end{array}$ & $\begin{array}{l}1(20) \\
3(60)\end{array}$ & $\begin{array}{c}1(20) \\
0\end{array}$ & $\begin{array}{l}0 \\
0\end{array}$ & $\begin{array}{l}0 \\
0\end{array}$ & $\begin{array}{l}2(40) \\
3(60)\end{array}$ & - \\
\hline
\end{tabular}

Sub-Substitution; Omi-Omission; Del-Deletion; Add-Addition

${ }^{*} \mathrm{P}$-value $<0.05$ was considered statistically significant

\begin{tabular}{|l|l|c|c|c|}
\hline \multicolumn{2}{|c}{ Table II: Case wise Distribution of Type of SSD, Sound Error and Level Distribution (n=5) } \\
\cline { 3 - 4 } \multirow{2}{*}{ Case } & \multirow{2}{*}{ SSD Type } & Original & Substituted & \multirow{2}{*}{ Level } \\
\hline 1 & Substitution & $/ \mathrm{k} /$ & $/ \mathrm{g} /$ & Initial \\
\hline 2 & Substitution & $/ \mathrm{t} /$ & $/ \mathrm{d} /$ & Middle \\
\hline 3 & Substitution & $/ \mathrm{f} /$ & - & Initial \\
\hline 4 & Omission & $/ \mathrm{t} /$ & - & All levels \\
\hline 5 & Omission & $/ \mathrm{g} /$ & & Middle \\
\hline
\end{tabular}

\section{Discussion}

The current study revealed the prevalence of SSD in public school children of Mandi Bahauddin District of Punjab, Pakistan. Out of a sample population of 377 students, aged 4-8 years, the prevalence of SSD was $1.3 \%(n=5)$. Different studies in the past have come up with widely variable prevalence rates. ${ }^{14}$ This might be due to variations in studies with regards to data collection tools; age groups; clinical versus non clinical setting; whether study was based on teacher, parent or speech language pathologist's report; cohort versus other studies and possible etiological factors. In majority, the possible etiology of SSD cannot be determined. Also the role of family history and recurrent otitis media with effusion in the early years of life as risk factors, has not been validated. ${ }^{15}$ Law et al., in a systematic review comprising of most studies from the west, noted a wide range of prevalence of SSD in 5 to 7 year old children ranging from 2 to $25 \% .{ }^{14}$ Wren et al. in a cohort study in 8 year old children reported a low prevalence of $3.5 \%,{ }^{16}$ while another cohort study also reported a lower range of $3.4 \% .{ }^{6}$ Eadie et al., in a large Australian community cohort study reported an SSD prevalence of $3.4 \%$ in 4 year old children. ${ }^{17}$ In contrast, a high prevalence rate of $17.6 \%$ was noted in a local school-based study on children aged 8 to 
12 years evaluated using articulation cards and checklists. ${ }^{18}$ Similarly, two Iranian studies revealed a high prevalence of $14.8 \%{ }^{19}$ and $9.5 \% .^{20}$ While in another Iranian study, Abbastabar et al., report a prevalence of 2 per 1000 people. ${ }^{21}$ In a school based study, Ceron et al., reported a prevalence of $15.26 \%$ phonological disorders. ${ }^{22}$

Gender wise, in the current study the prevalence rate was high in males $(4 ; 80 \%)$ as compared to females $(1 ; 20 \%)$, with a male to female ratio of $4: 1$. Similarly a higher prevalence in males was noted in other studies as well. ${ }^{16,21}$ Also a prevalence of $16.7 \%$ in males as compared to $12.7 \%$ in females was reported in an Iranian study. ${ }^{19}$

Genetic influence, ${ }^{23}$ gender, family history, mother's vocabulary, and socio-economic condition can predict development of SSD. ${ }^{17}$ Also, it is more common in rural residents compared to urban. ${ }^{21}$

In the current study, substitution was the commonest SSD with a frequency of $4(80 \%)$, followed by Omission in 1 (20\%). Similarly, in another local study by Azmat et al. substitution was most prevalent (92\%) followed by Omission in $6.25 \%$ and Distortion in $1.7 \% .{ }^{18}$ Similarly, in a study conducted in clinical setups of Rawalpindi Islamabad region, by Noveen et al. substitution was the commonest variety noted ${ }^{12}$ while $33 \%$ substitution, $60 \%$ distortion, $3 \%$ omission were reported in another local study. ${ }^{13}$

Though the prevalence of SSD is grossly variable, there is no recommendation of universal screening for primary speech language delay. ${ }^{24}$

There were several limitations of this study. The sample size was small, study was done in a government school setting with only 4 to 8 years old students included in the study. All these factors made generalization of our findings to other children of this age group and those studying in private schools, difficult. Lack of resources also limited the scope of this study as the research was self-funded.

\section{Conclusion}

The prevalence of Speech Sound Disorders in primary school children is very low being $1.3 \%$, with significantly higher prevalence in males, 5-6 years of age. "Substitution" of sounds is more common compared to "Omission" in the affected children.

\section{References}

1. Lewis BA, Freebairn L, Tag J, Ciesla AA, lyengar SK, Stein CM, et al. Adolescent outcomes of children with early speech sound disorders with and without language impairment. Am J Speech Lang Pathol. 2015; 24(2): 150-63. Doi: 10.1044/2014_AJSLP-140075.

2. McKinnon DH, McLeod S, Reilly S. The prevalence of stuttering, voice, and speech-sound disorders in primary school students in Australia. Lang Speech Hear Serv Sch. 2007; 38(1): 5-15.

3. Shriberg LD. Diagnostic markers for child speechsound disorders: introductory comments. Clin. Linguist. Phon. 2003; 17: 501-05. Doi: 10.1080/ 0269920031000138150

4. Tkach JA, Chen X, Freebairn LA, Schmithorst VJ, Holland $S$ K, Lewis B A. Neural correlates of phonological processing in speech sound disorder: a functional magnetic resonance imaging study. Brain Lang. 2011; 119: 42-49. Doi: 10.1016/j.bandl.2011 .02 .002

5. Lewis BA, Freebairn L, Tag J, Ciesla AA, lyengar SK, Stein CM, et al. Adolescent outcomes of children with early speech sound disorders with and without language impairment. Am J Speech Lang Pathol. 2015; 24(2): 150-63.

6. American Psychiatric Association. Diagnostic and Statistical Manual of Mental Disorders (DSM $-5^{\circledR}$ ). 5th ed. Arlington, VA: American Psychiatric Association; 2013. pp. 44-47.

7. Waring R, Knight R. How should children with speech sound disorders be classified? A review and critical evaluation of current classification systems. Int J Lang Commun Disord. 2013; 48(1): 25-40. 
8. Johnson C, Beitchman J, Brownlie E. Twenty-year follow-up of children with and without speechlanguage impairments: family, educational, occupational, and quality of life outcomes. Am J Speech Lang Pathol. 2010; 19(1): 51-65.

9. Siu AL. Screening for speech and language delay and disorders in children aged 5 years or younger: US Preventive Services Task Force recommendation statement. Pediatrics. 2015; 136(2): e474-81.

10. Arshad H, Ghayas MS, Madiha, Ghayas R, ul Ain Q, Shabbir M. Patterns and Risk Factors Associated with Speech Sounds and Language Disorders in Pakistan. Ann King Edw Med Univ. 2013; 19(3): 226-30.

11. Wallace IF, Berkman ND, Watson LR, Coyne-Beasley $\mathrm{T}$, Wood CT, Cullen K, et al. Screening for speech and language delay in children 5 years old and younger: a systematic review. Pediatrics. 2015; 136(2): e448e462. Doi:10.1542/peds.2014-3889

12. Noveen S, Butt AK, Alam MB. Development of a test for articulation and phonological disorders in Urdu speaking children. JRCRS. 2017; 5(2): 89-93.

13. Noveen S, Ullah SH, Alam B. Correlation Between Articulation Disorders and Oral Motor Mechanism. Ann King Edw Med Univ. 2018; 24(1): 653-58.

14. Law J, Boyle J, Harris F, Harkness A, Nye C. Prevalence and natural history of primary speech and language delay: findings from a systematic review of the literature. Int J Lang Commun Disord. 2000; 35(2): 165-88.

15. Wertzner HF, Francisco DT, Pagan-Neves LO. Causal factors and application of complementary tests in speech sound disorders. RSBF. 2012; 17(3): 299-303.

16. Wren Y, Miller LL, Peters TJ, Emond A, Roulstone S. Prevalence and Predictors of Persistent Speech Sound Disorder at Eight Years Old: Findings from a Population Cohort Study. J Speech Lang Hear Res. 2016; 59(4): 647-73.
17. Eadie $P$, Morgan A, Ukoumunne OC, Ttofari Eecen $K$, Wake M, Reilly S. Speech sound disorder at 4 years: prevalence, comorbidities, and predictors in a community cohort of children. Dev Med Child Neurol. 2015; 57(6): 578-84. Doi: 10.1111/dmcn.12635

18. Azmat R, Khan MS, Manzoor T, Ibrahim M, Tahira S, Pervaiz S. Prevalence of articulation disorder in school going children between ages of 8 to 12 years. Int. J Rehabil. Sci.2014; 3: 32-36.

19. Karbasi SA, Fallah R, Golestan M. The prevalence of speech disorder in primary school students in YazdIran. Acta Medica Iranica. 2011; 49(1): 33-7.

20. Hatami G, Heidaritash H, Firouzbakht S, Motamed N. [The Frequency of Speech Disorders and Its Relationship with Nutritive and Non-Nutritive Sucking Behaviors in 3-5 Years Old Children in Bushehr, City, Iran (Persian)]. Arch Rehabil. 2018; 19(3): 238-49. Doi: 10.32598/rj.19.3.238

21. Abbastabar $H$, Alizadeh A, Darparesh M, Mohseni S, Roozbeh N. Spatial distribution and the prevalence of speech disorders in the provinces of Iran. J Med Life. 2015; 8(Spec Iss 2): 99-104.

22. Ceron MI, Gubiani MB, de Oliveira CR, Gubiani MB, Soares MK. Prevalence of phonological disorders and phonological processes in typical and atypical phonological development. CoDAS 2017; 29(3): e20150306 Doi: 10.1590/2317-1782/20172015306

23. Stein CM, Millard C, Kluge A, Miscimarra LE, Cartier KC, Freebairn LA, et al. Speech sound disorder influenced by a locus in 15q14 region. Behav Genet. 2006; 36(6): 858-68.

24. Law J, Boyle J, Harris F, Harkness A, Nye C. The feasibility of universal screening for primary speech and language delay: Findings from a systematic review of the literature. Dev Med Child Neurol. 2000; 42(3): 190-200. 